\title{
Aggravated Malignant Neoplasm
}

National Cancer Institute

\section{Source}

National Cancer Institute. Aggravated Malignant Neoplasm. NCI Thesaurus. Code C3851.

A malignant neoplasm that shows clinical and/or pathologic progression. 